PREPARED FOR THE U.S. DEPARTMENT OF ENERGY, UNDER CONTRACT DE-AC02-76CH03073

PPPL-3726

PPPL-3726

UC-70

\title{
Plasma Performance Improvements with Liquid Lithium Limiters in CDX-U
}

by

R. Majeski, M. Boaz, D. Hoffman, B. Jones, R. Kaita, H. Kugel, T. Munsat, J. Spaleta, V. Soukhanovskii, J. Timberlake,

L. Zakharov, G. Antar, R. Doerner, S. Luckhardt, R.W. Conn, M. Finkenthal, D. Stutman, R. Maingi, and M. Ulrickson

July 2002
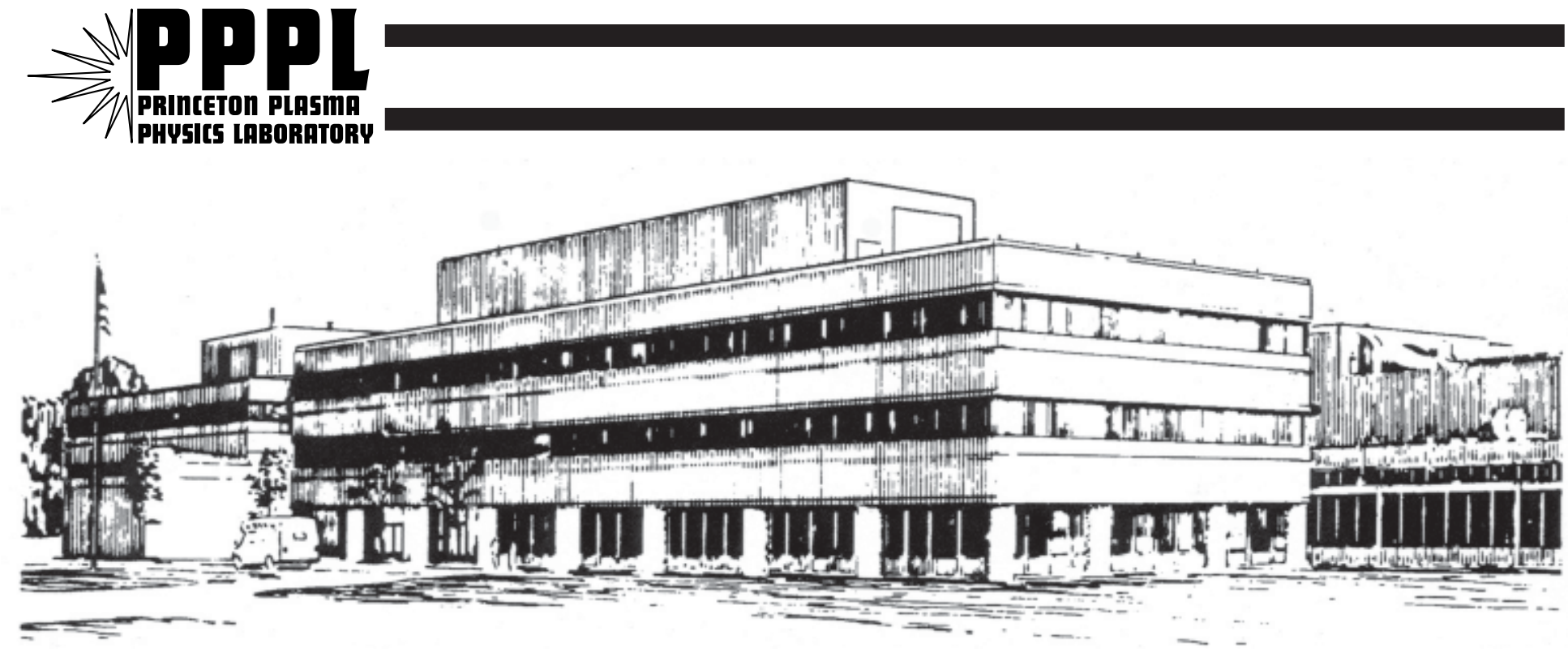

PRINCETON PLASMA PHYSICS LABORATORY PRINCETON UNIVERSITY, PRINCETON, NEW JERSEY 


\section{PPPL Reports Disclaimer}

This report was prepared as an account of work sponsored by an agency of the United States Government. Neither the United States Government nor any agency thereof, nor any of their employees, makes any warranty, express or implied, or assumes any legal liability or responsibility for the accuracy, completeness, or usefulness of any information, apparatus, product, or process disclosed, or represents that its use would not infringe privately owned rights. Reference herein to any specific commercial product, process, or service by trade name, trademark, manufacturer, or otherwise, does not necessarily constitute or imply its endorsement, recommendation, or favoring by the United States Government or any agency thereof. The views and opinions of authors expressed herein do not necessarily state or reflect those of the United States Government or any agency thereof.

\section{Availability}

This report is posted on the U.S. Department of Energy's Princeton Plasma Physics Laboratory Publications and Reports web site in Fiscal Year 2002. The home page for PPPL Reports and Publications is: http://www.pppl.gov/pub_report/

DOE and DOE Contractors can obtain copies of this report from:

U.S. Department of Energy

Office of Scientific and Technical Information

DOE Technical Information Services (DTIS)

P.O. Box 62

Oak Ridge, TN 37831

Telephone: (865) 576-8401

Fax: (865) 576-5728

Email: reports@adonis.osti.gov

This report is available to the general public from:

National Technical Information Service

U.S. Department of Commerce

5285 Port Royal Road

Springfield, VA 22161

Telephone: 1-800-553-6847 or

(703) 605-6000

Fax: (703) 321-8547

Internet: http://www.ntis.gov/ordering.htm 
Plasma Performance Improvements with Liquid Lithium Limiters in CDX-U

\author{
R. Majeski ${ }^{1)}$, M. Boaz ${ }^{1)}$, D. Hoffman ${ }^{1)}$, B. Jones ${ }^{1)}$, R. Kaita ${ }^{1)}$, H. Kugel $^{1)}$, T. Munsat $^{1)}$, J. \\ Spaleta $^{1)}$, V. Soukhanovskii ${ }^{1)}$, J. Timberlake ${ }^{1)}$, L. Zakharov ${ }^{1)}$, G. Antar ${ }^{2}$, R. Doerner ${ }^{2)}$, S. \\ Luckhardt $^{2)}$, R. W. Conn ${ }^{2)}$, M. Finkenthal ${ }^{3)}$, D. Stutman ${ }^{3)}$, R. Maingi ${ }^{4)}$, M. Ulrickson ${ }^{5)}$

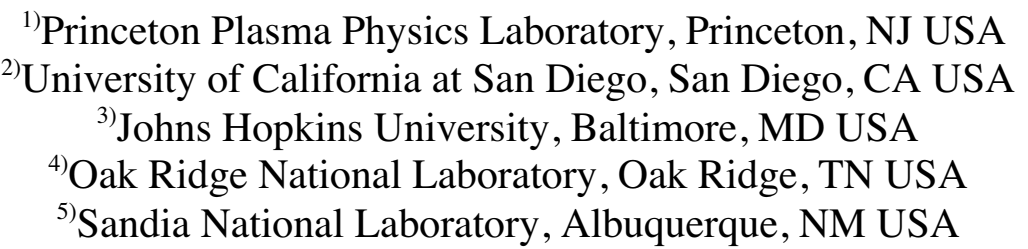

Abstract: The use of flowing liquid lithium as a first wall for a reactor has potentially attractive physics and engineering features. The Current Drive eXperiment - Upgrade (CDX-U) at the Princeton Plasma Physics Laboratory has begun experiments with a fully toroidal liquid lithium limiter. $\mathrm{CDX}-\mathrm{U}$ is a compact $\left(\mathrm{R}=34 \mathrm{~cm}, \mathrm{a}=22 \mathrm{~cm}, \mathrm{~B}_{\text {toroidal }}=2 \mathrm{kG}, \mathrm{I}_{\mathrm{P}}\right.$ $\left.=100 \mathrm{kA}, \mathrm{T}_{\mathrm{e}}(0) \sim 100 \mathrm{eV}, \mathrm{n}_{\mathrm{e}}(0) \sim 5 \times 10^{19} \mathrm{~m}^{-3}\right)$ short-pulse $(<25 \mathrm{msec})$ spherical tokamak with extensive diagnostics. The limiter, which consists of a shallow circular stainless steel tray of radius $34 \mathrm{~cm}$ and width $10 \mathrm{~cm}$, can be filled with lithium to a depth of a few millimeters, and forms the lower limiting surface for the discharge. Heating elements beneath the tray are used to liquefy the lithium prior to the experiment. The total area of the tray is approximately $2000 \mathrm{~cm}^{2}$. The tokamak edge plasma, when operated in contact with the lithium-filled tray, shows evidence of reduced impurities and recycling. The reduction in recycling and impurities is largest when the lithium is liquefied by heating to $250{ }^{\circ} \mathrm{C}$. Discharges which are limited by the liquid lithium tray show evidence of performance enhancement. Radiated power is reduced and there is spectroscopic evidence for increases in the core electron temperature. Furthermore, the use of a liquid lithium limiter reduces the need for conditioning discharges prior to high current operation. The future development path for liquid lithium limiter systems in CDX-U is also discussed.

PACS codes: 52.40.Hf, 52.55.Fa, 28.52.Fa

Keywords: lithium, tokamak, limiter

Corresponding Author: Richard Majeski, Princeton Plasma Physics Laboratory - MS17, P. O. Box 451, Princeton, NJ 08543 USA. Phone: 609243 3112. Fax: 6092432418.

Email: rmajeski@pppl.gov 
The use of liquid lithium as a plasma facing component (PFC) is presently undergoing tests at the PISCES-B divertor simulator facility,[1] the T11-M tokamak,[2] and the Current Drive experiment - Upgrade (CDX-U) at the Princeton Plasma Physics Laboratory. $\mathrm{CDX}-\mathrm{U}$ is a spherical tokamak with major radius $\mathrm{R}_{0}=34 \mathrm{~cm}$, minor radius $\mathrm{a}=22 \mathrm{~cm}$, a toroidal magnetic field of $2 \mathrm{kG}$, peak plasma current of less than $100 \mathrm{kA}$, central electron temperature $\mathrm{T}_{\mathrm{e}}(0) \sim 100 \mathrm{eV}$, central electron density $\mathrm{n}_{\mathrm{e}}(0) \sim 5 \times 10^{19} \mathrm{~m}^{-3}$, with a modest pulse duration of $25 \mathrm{msec}$. or less. The experiment has extensive spectroscopic and other diagnostics to determine edge and core concentrations of lithium and other impurities. A 12 point Thomson scattering system is installed on CDX-U; however, for the experiments presented here the system was inoperable. The CDX-U experiments[3] described here focus on the use of large area, free surface, liquid lithium plasma facing components (PFCs).

The first experiments with lithium systems in CDX-U utilized a rail limiter $[1,4]$ with a lithium-wet mesh, a system which is somewhat similar to the T11-M capillary limiter.[2] The rail limiter experiments were intended to explore the deployment of a small liquid lithium system in a tokamak. In that sense, the experiments were successful, since the limiter was installed, operated, and removed without problem. The lithium rail limiter did not, however, produce a significant effect on plasma performance. Following the completion of the rail limiter experiments, a circular tray $34 \mathrm{~cm}$ in radius, $10 \mathrm{~cm}$ wide, and $0.5 \mathrm{~cm}$ deep was mounted on the bottom of the CDX-U vacuum vessel and loaded with lithium. A view of the interior of $\mathrm{CDX}-\mathrm{U}$ with the tray installed, prior to pumpdown, is shown in Figure 1. If the tray is uniformly filled with liquid lithium, it presents an area of $2000 \mathrm{~cm}^{2}$ to the plasma. 
The tray limiter is fitted with resistive disk heaters clamped to the lower surface, which are capable of heating the tray to $400{ }^{\circ} \mathrm{C}$, well in excess of the melting point of lithium $\left(180^{\circ} \mathrm{C}\right)$. The tray was typically heated to $250{ }^{\circ} \mathrm{C}$ to liquefy the lithium. During operation of CDX-U, the tray serves as a fully toroidal limiter for the discharge, and hence forms a principal PFC for CDX-U.

However, the tray has not been uniformly wet by the lithium, so that perhaps $50 \%$ of the tray is uncoated stainless steel. The thickness of the lithium layer in the tray varies from 0 to $8-9 \mathrm{~mm}$. The lithium exhibits varying degrees of coating, which were only partially removed by extensive argon glow discharge cleaning. An unforeseen consequence of the insulating coatings acquired by the lithium in the tray was that unipolar arcing to the lithium was common during initial operation with the limiter. $\mathbf{J} \times \mathbf{B}$ forces produced during the short-lived arcs ejected small droplets of lithium from the tray. The droplets formed an irregular coating on the lower heat shields in the CDX-U vacuum chamber, but had no apparent consequences for tokamak performance. A more complete history of tray commissioning has been given elsewhere.[3,5] Here we principally note that despite coatings, and the uneven layer of lithium filling the tray, there are strong indications of plasma performance improvements through the use of liquid lithium PFCs.

During operation with the tray limiter the edge oxygen, $\mathrm{D}_{\alpha}$, carbon and lithium emission was monitored by a spectroscopy system developed at the Oak Ridge National Laboratory. The system views on the order of $100 \mathrm{~cm}^{2}$ of tray area from above. The intensity of emission at the time of peak plasma current was then extracted, for discharges which used the empty stainless steel tray as a limiter, for discharges which 
used a room-temperature lithium filled tray as a limiter, and for discharges in which the tray was heated to $250{ }^{\circ} \mathrm{C}$, well above the melting point of lithium. The data for OII emission at $4416 \AA$ is shown in Figure 2. Operation with solid lithium in the tray results in lowered edge oxygen emission than operation with the bare stainless steel tray. Liquefying the lithium results in a further reduction in edge oxygen. The data for the three tray conditions is segregated; the oxygen emission for the liquid lithium case is lowest, followed by the solid lithium and then the bare tray data. There is a clear trend toward higher plasma current as the oxygen emission drops. Prior to obtaining the data sets for any tray fill condition the limiter and fill were argon glow discharge cleaned for several hours. Note also that the data for discharges limited on liquid lithium was taken prior to the data with a solid lithium limiter, so that the improvement in performance with liquid lithium cannot be ascribed to a gradual day-to-day conditioning effect.

Figure 3 is a plot of the edge carbon emission from the CIII line at $4650 \AA$ for the cases of a solid and a liquid lithium fill in the tray. CIII data is not available for discharges limited by the bare stainless steel tray. There is a trend toward lower carbon in discharges with higher peak operating current, but the edge carbon emission is roughly comparable for both the liquid and solid lithium cases, for similar plasma current.

Figure 4 is a plot of $D_{\alpha}$ emission in the edge plasma at the tray, for solid and liquid lithium. $\mathrm{D}_{\alpha}$ emission data for the bare tray is not available. Virtually all the discharges with liquid lithium in the tray show reduced $\mathrm{D}_{\alpha}$ emission compared to the discharges with solid lithium. This result agrees with previously obtained data indicating that the recycling coefficient for hydrogenic species on liquid lithium is very low.[1] Hydrogen implanted in the liquid lithium is able to diffuse rapidly out of the implantation 
zone into the bulk liquid metal,[6] whereas hydrogen implanted in solid lithium saturates the surface. It should also be stressed that the viewed area represented in Figure 4 is partly covered with lithium, and some of the lithium is oxide coated. Therefore, the residual recycling seen in the data with liquid lithium may be due to the contribution from a small bare area on the tray, or a coated area on the lithium fill. Reduced $D_{\alpha}$ emission is also correlated with increased plasma current.

The area of the tray which is filled with lithium represents approximately $20 \%$ of the total PFC area in contact with the plasma, in a typical CDX-U discharge. The centerstack constitutes the principle remaining PFC. Despite the fact that the lithium in the tray represents a small fraction of the total plasma facing area, enhancements in global plasma performance have been observed in operation with the liquid lithium limiter. One indication of enhanced global performance was that a general reduction in the total radiated power was seen for discharges operated in contact with either solid or liquid lithium., as shown in Figure 5.

For the electron temperature range in which CDX-U operates $(\sim 100 \mathrm{eV})$, the level of soft $\mathrm{X}$-ray emission from carbon $\mathrm{V}$ is a good indicator of the electron temperature. Carbon V emission for the cases of a bare, solid lithium filled, and liquid lithium filled tray is shown in Figure 6. Discharges limited by solid lithium show somewhat higher CV emission (and hence higher core electron temperatures) than the discharges limited by the bare stainless steel tray. However, the majority of discharges limited by liquid lithium show significant increases in the level of CV emission over those limited either by the bare tray or solid lithium. For discharges in which the carbon concentration does not vary 
significantly, as shown by the edge carbon data shown in Figure 4, this increase in emission is indicative of higher core electron temperatures.

Somewhat higher peak plasma currents were also obtained in discharges limited by liquid lithium.[5,7] Since CDX-U is operated at constant loop voltage rather than feedback controlled for constant plasma current, higher plasma currents are also indicative of cleaner, hotter plasmas. Loop voltage consumption is also slightly lower for plasmas limited on liquid lithium than for plasmas limited on stainless steel or solid lithium, although the magnitude of the reduction is small.

Lithium III emission from the core plasma at $135 \AA$ is also monitored with a multichord, multilayer mirror array, provided by the spectroscopy group at Johns Hopkins University. The emission data, at the time of peak ohmic current, is shown in Figure 7. Data from the bare tray provides a baseline. Li III emission from plasmas limited on solid and liquid lithium is comparable, and does not show a dependence on plasma current. A quantitative estimate of the core lithium concentration from this data is feasible, but is not yet available.

In the near term, the existing tray limiter will be replaced. New filling and discharge cleaning techniques developed in collaboration with the PISCES group at the University of California at San Diego will be implemented, in an attempt to obtain a uniform lithium fill of the new tray, with a clean surface. Following experiments with the new tray and fill system, an internally circulating liquid lithium limiter will be installed in CDX-U next year. Experiments will be expanded to include the induction of $\mathbf{J} \times \mathbf{B}$ and ponderomotive forces to restrain the liquid metal during a discharge. 
In CDX-U, most plasma material interactions take place at the centerstack which is coated with titanium nitride. In the longer term, it is desirable to eliminate all plasma surface interactions with materials other than liquefied lithium, in order to determine the effect of very low recycling on the confined plasma. A proposal to install a conformal shell in CDX-U, along with an electron beam evaporation system capable of depositing several hundred angstroms of lithium over the entire inner surface of the shell between discharges, has been made.

This work was supported by USDOE Contract No. DE-AC02-76-CHO3073. 


\section{$\underline{\text { References }}$}

[1] S. Luckhardt et al., Proc. $19^{\text {th }}$ IEEE/NPSS Symposium on Fusion Engineering, Atlantic City, NJ (2002)

[2] V. A. Evitkhin et al., in Proc. $18^{\text {th }}$ IAEA Fusion Energy Conf., Sorrento, Italy 4-10

October 2000, paper IAEA-CN-77/EXP4/21

[3] R. Kaita et al., $6^{\text {th }}$ Int. Symposium on Fusion Nuclear Technology, San Diego, CA (2002). To be published in Fus. Eng. Des.

[4] G. Antar et al., to be published in Fus. Eng. Des.

[5] R. Majeski et al., Proc. $19^{\text {th }}$ IEEE/NPSS Symposium on Fusion Engineering, Atlantic City, NJ (2002)

[6] H. Moriayama, K. Iwasaki and Y. Ito, J. Nucl. Mater. 191-194, 190 (1992)

[7] R. Majeski et al, submitted to Fus. Eng. Des. 


\section{Figure Captions}

Figure 1. Photograph of the interior of CDX-U showing the tray limiter, centerstack heat shields, and lower vessel shield plates.

Figure 2. Oxygen II emission at the surface of the tray, for discharges limited by the empty tray, a solid lithium fill, and a liquid lithium fill.

Figure 3. CIII emission at $4650 \AA$ from the edge plasma adjacent to the lithium tray limiter, for solid and liquid lithium.

Figure 4. $\mathrm{D}_{\alpha}$ emission at the lithium filled tray, for solid and liquid lithium limited discharges.

Figure 5. Total radiated power, from the CDX-U tangential bolometer array, for discharges limited by the bare stainless steel tray, solid lithium, and liquid lithium. Figure 6. Soft X-ray (CV) emission from CDX-U, for discharges limited by the bare stainless steel tray, solid lithium, and liquid lithium. The increase for the case of liquid lithium indicates a significant (perhaps 2-3 x) increase in the peak electron temperature, in comparison to the bare tray and solid lithium cases.

Figure 7. Lithium III emission at $135 \AA$ for plasmas limited by the bare tray (baseline data), solid lithium, and liquid lithium. 


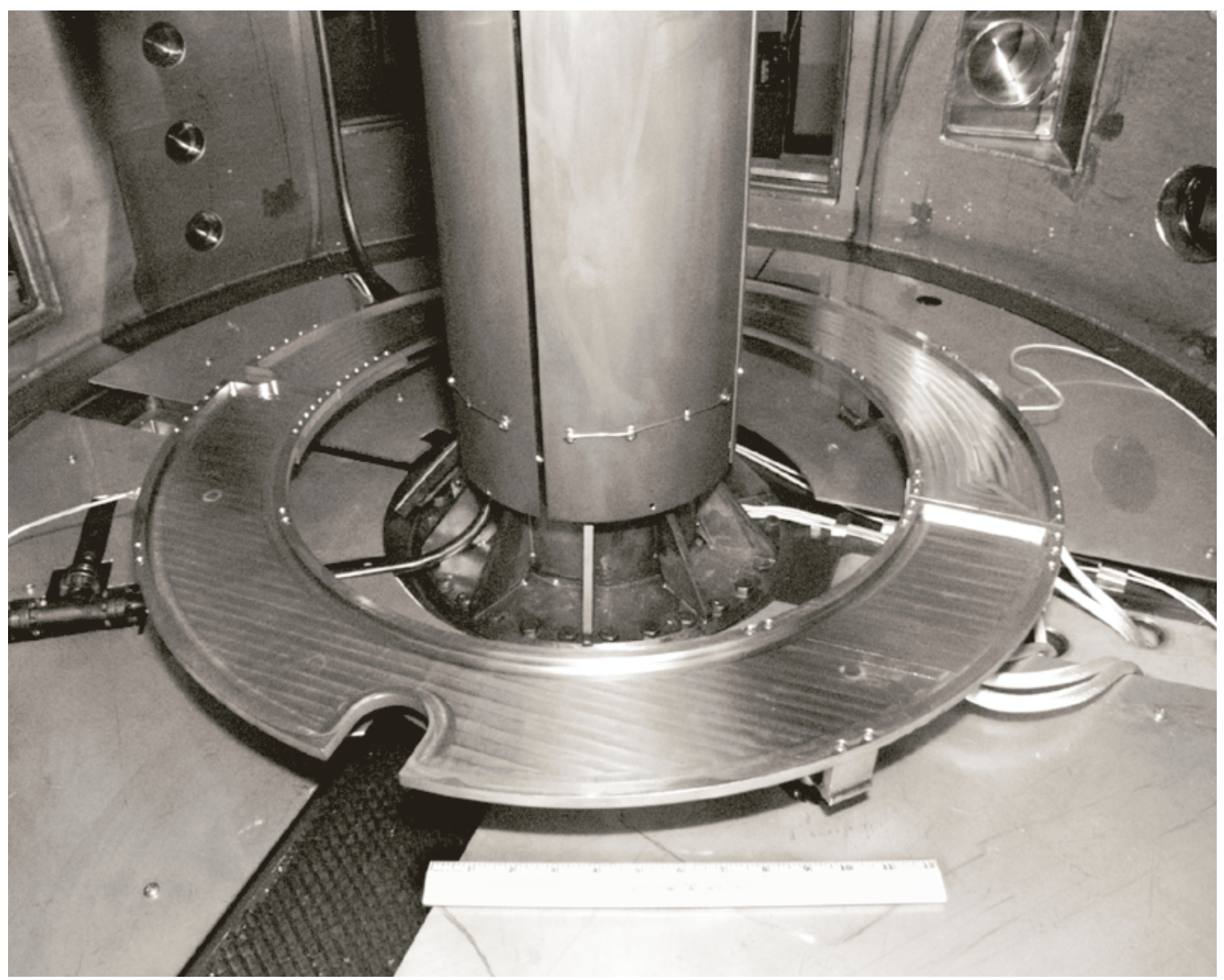

Figure 1. Photograph of the interior of CDX-U showing the tray limiter, centerstack heat shields, and lower vessel shield plates. 


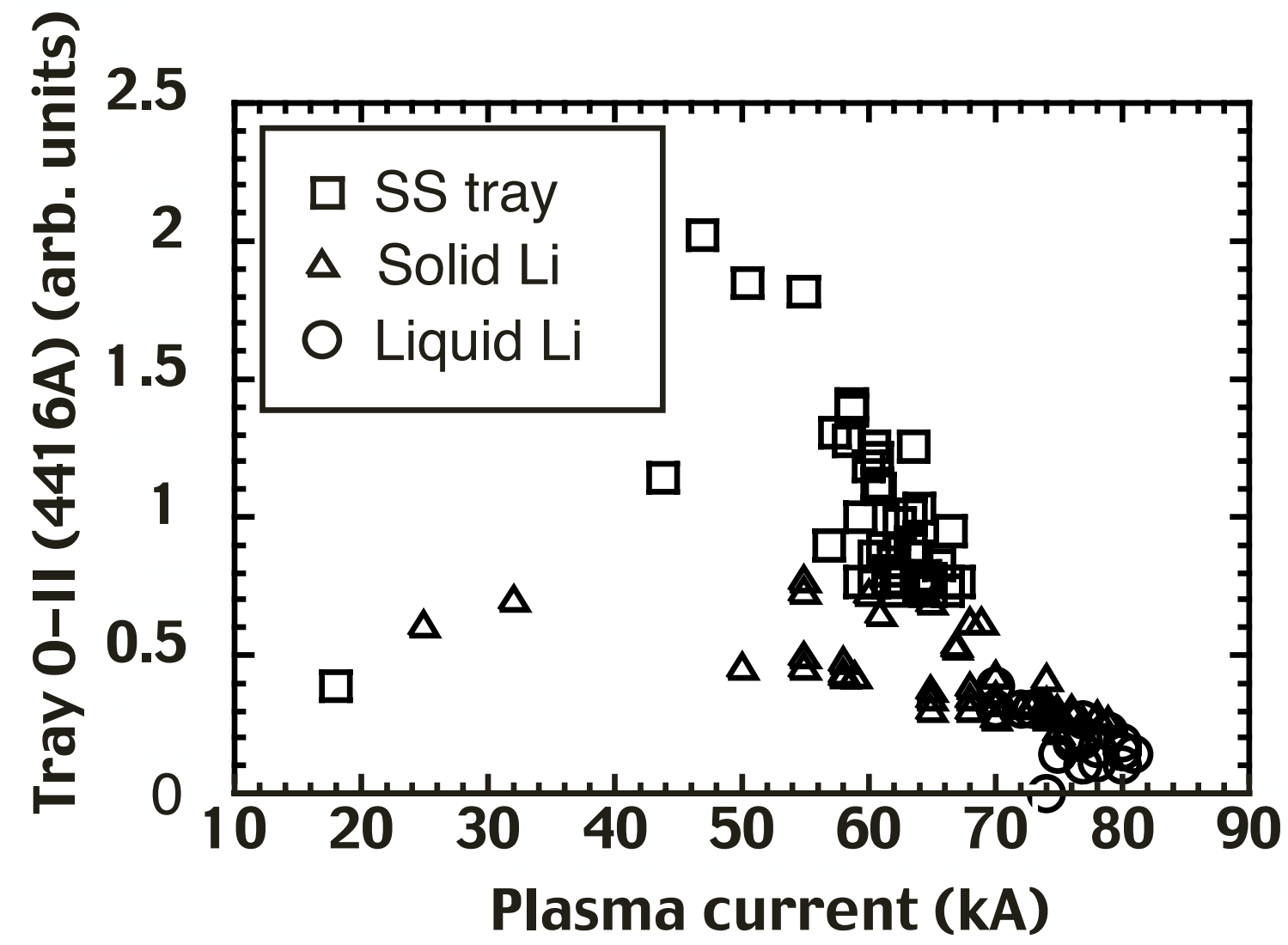

Figure 2. Oxygen II emission at the surface of the tray, for discharges limited by the empty tray, a solid lithium fill, and a liquid lithium fill. 


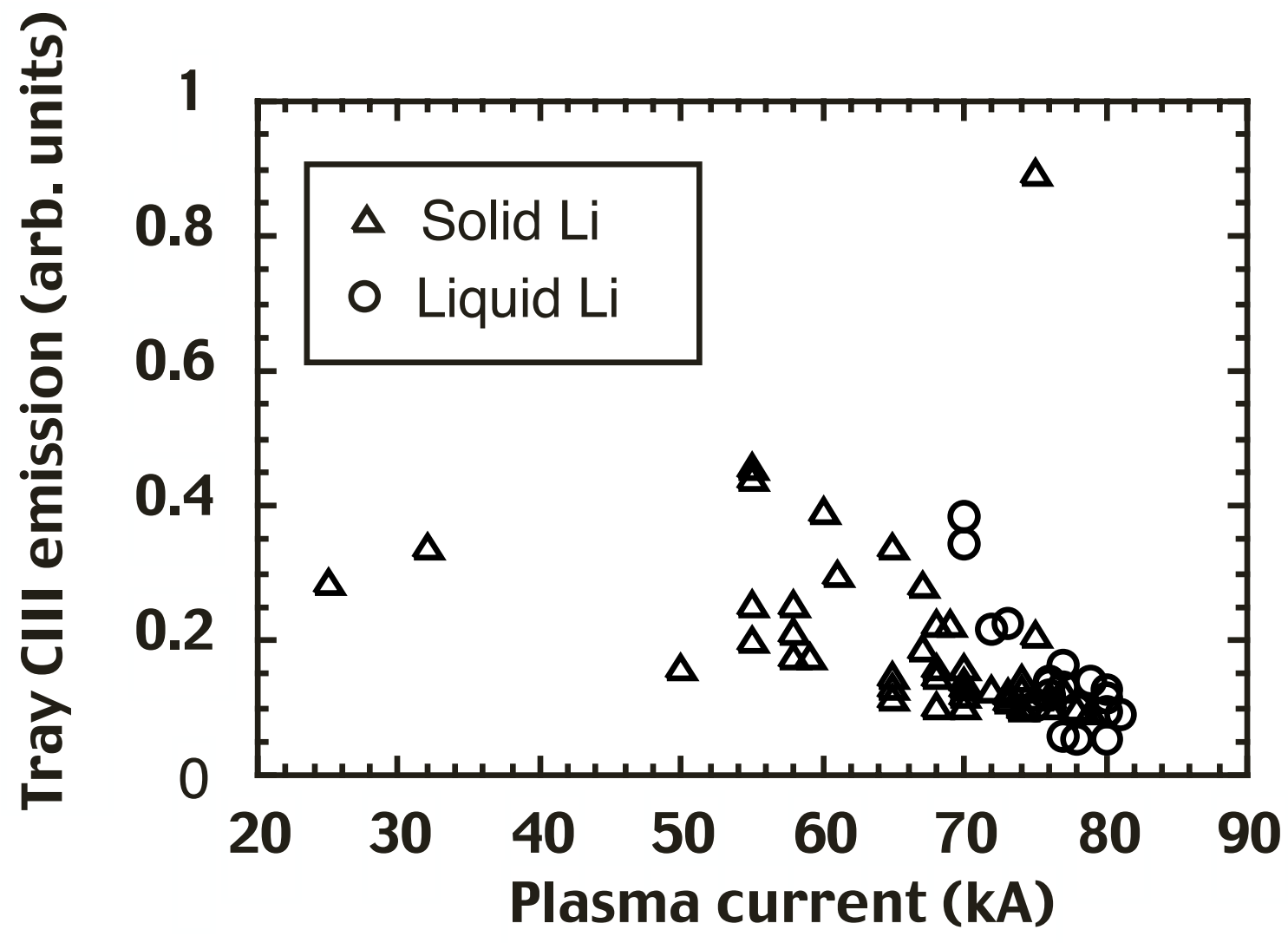

Figure 3. CIII emission at $4650 \AA$ from the edge plasma adjacent to the lithium tray limiter, for solid and liquid lithium. 


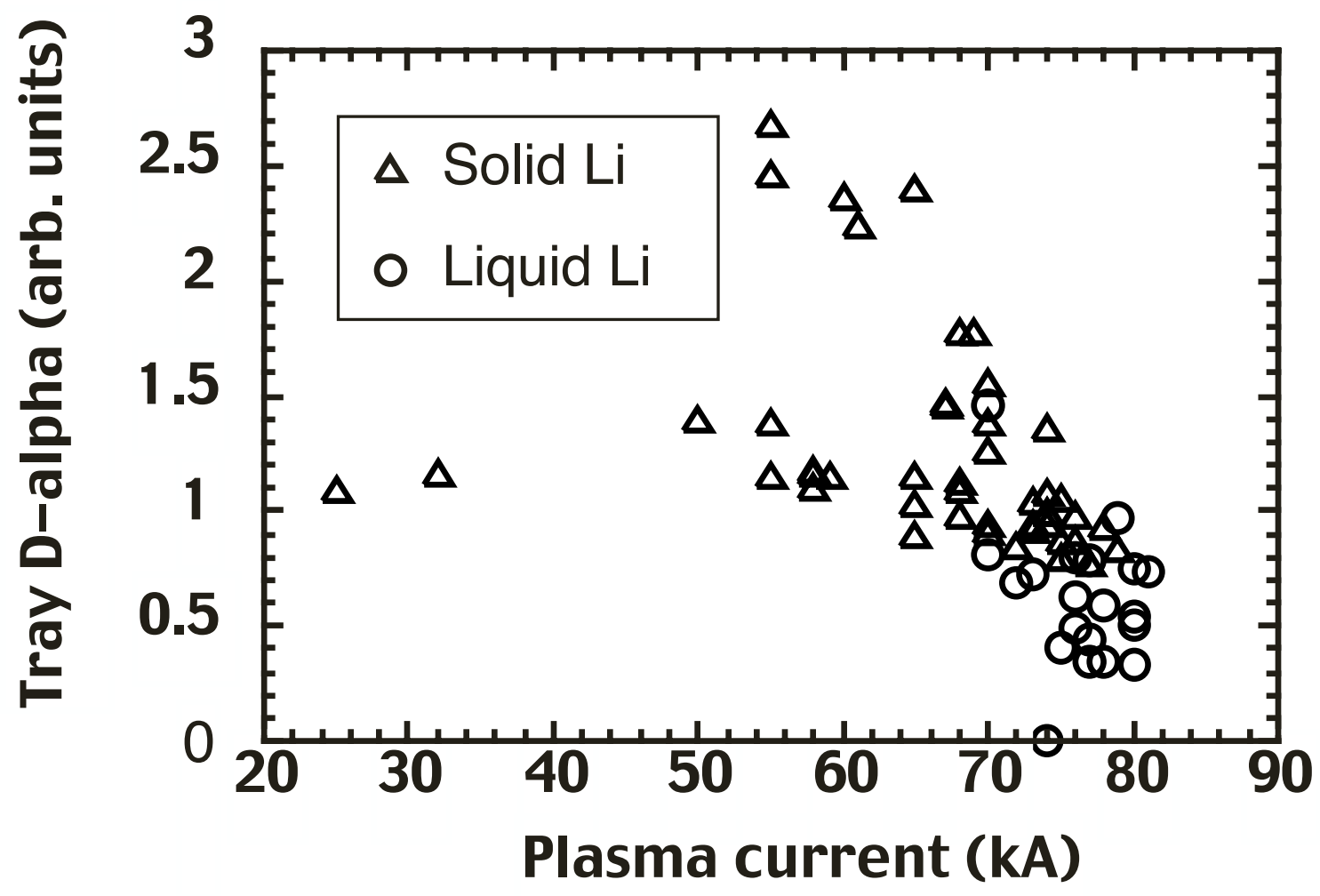

Figure 4. $\mathrm{D}_{\alpha}$ emission at the lithium filled tray, for solid and liquid lithium limited discharges. 


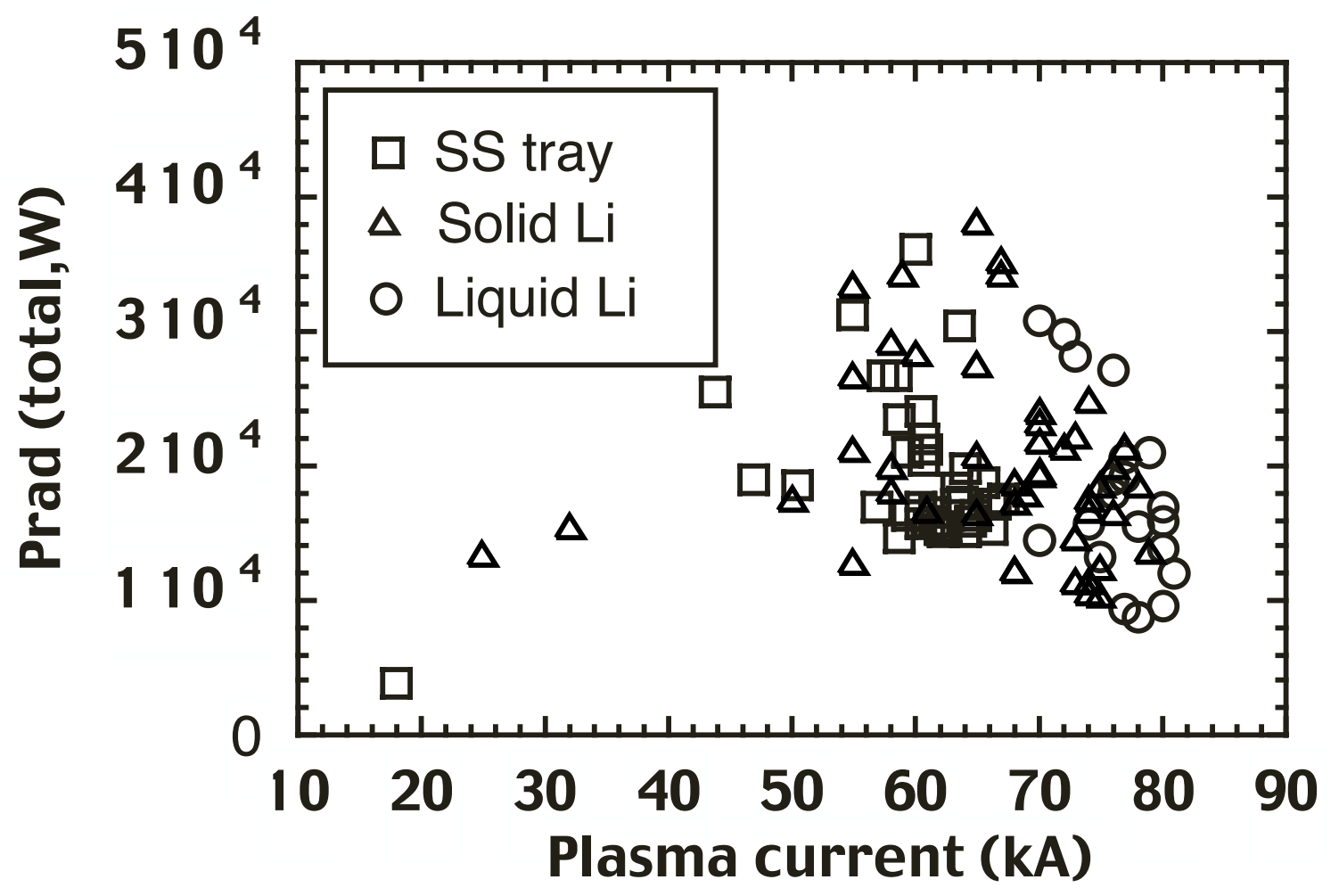

Figure 5. Total radiated power, from the CDX-U tangential bolometer array, for discharges limited by the bare stainless steel tray, solid lithium, and liquid lithium. 


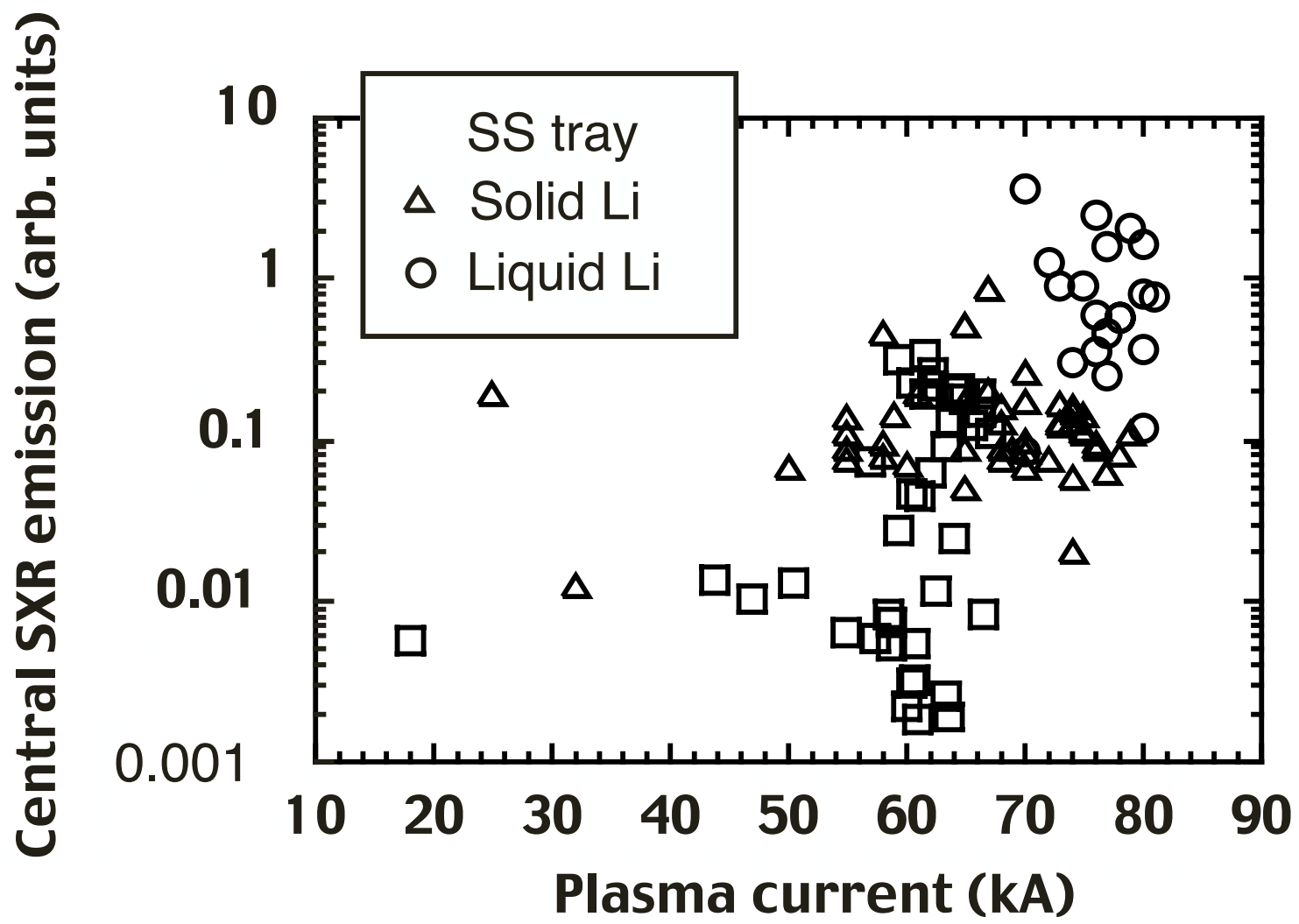

Figure 6. Soft X-ray (CV) emission from CDX-U, for discharges limited by the bare stainless steel tray, solid lithium, and liquid lithium. The increase for the case of liquid lithium indicates a significant (perhaps 2-3 x) increase in the peak electron temperature, in comparison to the bare tray and solid lithium cases. 


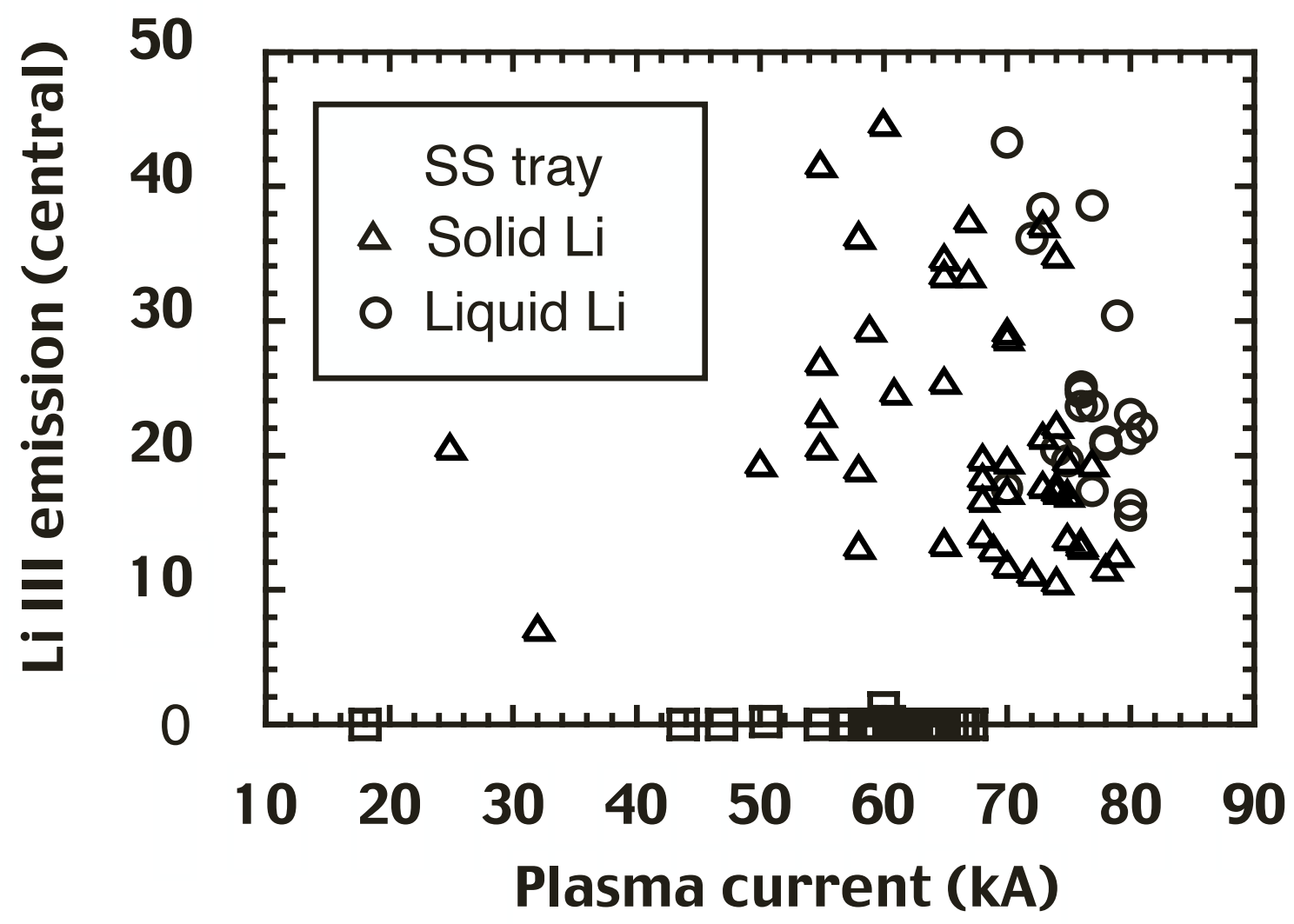

Figure 7. Lithium III emission at $135 \AA$ for plasmas limited by the bare tray (baseline data), solid lithium, and liquid lithium. 


\section{External Distribution}

Plasma Research Laboratory, Australian National University, Australia

Professor I.R. J ones, Flinders University, Australia

Professor J oão Canalle, Instituto de Fisica DEQ/IF - UERJ , Brazil

Mr. Gerson O. Ludwig, Instituto Nacional de Pesquisas, Brazil

Dr. P.H. Sakanaka, Instituto Fisica, Brazil

The Librarian, Culham Laboratory, England

Library, R61, Rutherford Appleton Laboratory, England

Mrs. S.A. Hutchinson, JET Library, England

Professor M.N. Bussac, Ecole Polytechnique, France

Librarian, Max-Planck-Institut für Plasmaphysik, Germany

J olan Moldvai, Reports Library, MTA KFKI-ATKI, Hungary

Dr. P. Kaw, Institute for Plasma Research, India

Ms. P.J . Pathak, Librarian, Insitute for Plasma Research, India

Ms. Clelia De Palo, Associazione EURATOM-ENEA, I taly

Dr. G. Grosso, Instituto di Fisica del Plasma, Italy

Librarian, Naka Fusion Research Establishment, J AERI, J apan

Library, Plasma Physics Laboratory, Kyoto University, J apan

Research Information Center, National Institute for Fusion Science, J apan

Dr. O. Mitarai, Kyushu Tokai University, J apan

Library, Academia Sinica, Institute of Plasma Physics, People's Republic of China

Shih-Tung Tsai, Institute of Physics, Chinese Academy of Sciences, People's Republic of China

Dr. S. Mirnov, TRINITI, Troitsk, Russian Federation, Russia

Dr. V.S. Strelkov, Kurchatov Institute, Russian Federation, Russia

Professor Peter Lukac, Katedra Fyziky Plazmy MFF UK, Mlynska dolina F-2, Komenskeho Univerzita, SK-842 15 Bratislava, Slovakia

Dr. G.S. Lee, Korea Basic Science Institute, South Korea

Mr. Dennis Bruggink, Fusion Library, University of Wisconsin, USA

Institute for Plasma Research, University of Maryland, USA

Librarian, Fusion Energy Division, Oak Ridge National Laboratory, USA

Librarian, Institute of Fusion Studies, University of Texas, USA

Librarian, Magnetic Fusion Program, Lawrence Livermore National Laboratory, USA

Library, General Atomics, USA

Plasma Physics Group, Fusion Energy Research Program, University of California at San Diego, USA

Plasma Physics Library, Columbia University, USA

Alkesh Punjabi, Center for Fusion Research and Training, Hampton University, USA

Dr. W.M. Stacey, Fusion Research Center, Georgia Institute of Technology, USA

Dr. J ohn Willis, U.S. Department of Energy, Office of Fusion Energy Sciences, USA

Mr. Paul H. Wright, Indianapolis, Indiana, USA 
The Princeton Plasma Physics Laboratory is operated by Princeton University under contract with the U.S. Department of Energy.

\author{
Information Services \\ Princeton Plasma Physics Laboratory \\ P.O. Box 451 \\ Princeton, NJ 08543
}

Phone: 609-243-2750

Fax: 609-243-2751

e-mail: pppl_info@pppl.gov

Internet Address: http://www.pppl.gov 